\title{
ARTICLE \\ Deep phenotyping in 3q29 deletion syndrome: recommendations for clinical care
}

\author{
Rossana Sanchez Russo ${ }^{1,11}$, Michael J. Gambello ${ }^{1,11}$, Melissa M. Murphy ${ }^{1,11}$, Katrina Aberizk ${ }^{5}$, Emily Black ${ }^{1}$, T. Lindsey Burrell ${ }^{2,3}$, \\ Grace Carlock ${ }^{1}$, Joseph F. Cubells ${ }^{1,4}$, Michael T. Epstein ${ }^{4}$, Roberto Espana ${ }^{5}$, Katrina Goines ${ }^{5}$, Ryan M. Guest ${ }^{5}$, Cheryl Klaiman $^{2,3}$, \\ Sookyong Koh ${ }^{2}$, Elizabeth J. Leslie ${ }^{1}$, Longchuan $\mathrm{Li}^{2,3}$, Derek M. Novacek ${ }^{6,7}$, Celine A. Saulnier ${ }^{2,8}$, Esra Sefik ${ }^{1,5}$, Sarah Shultz ${ }^{2,3}$, \\ Elaine Walker ${ }^{5}$, Stormi Pulver White ${ }^{2,3}$, The Emory 3q29 Project* and Jennifer Gladys Mulle (iD) ${ }^{1,9 凶}$
}

PURPOSE: To understand the consequences of the 3q29 deletion on medical, neurodevelopmental, psychiatric, brain structural, and neurological sequalae by systematic evaluation of affected individuals. To develop evidence-based recommendations using these data for effective clinical care.

METHODS: Thirty-two individuals with the 3q29 deletion were evaluated using a defined phenotyping protocol and standardized data collection instruments.

RESULTS: Medical manifestations were varied and reported across nearly every organ system. The most severe manifestations were congenital heart defects $(25 \%)$ and the most common were gastrointestinal symptoms ( $81 \%)$. Physical examination revealed a high proportion of musculoskeletal findings (81\%). Neurodevelopmental phenotypes represent a significant burden and include intellectual disability (34\%), autism spectrum disorder (38\%), executive function deficits (46\%), and graphomotor weakness (78\%). Psychiatric illness manifests across the lifespan with psychosis prodrome (15\%), psychosis (20\%), anxiety disorders (40\%), and attention deficit-hyperactivity disorder (ADHD) (63\%). Neuroimaging revealed structural anomalies of the posterior fossa, but on neurological exam study subjects displayed only mild or moderate motor vulnerabilities.

CONCLUSION: By direct evaluation of 3q29 deletion study subjects, we document common features of the syndrome, including a high burden of neurodevelopmental and neuropsychiatric phenotypes. Evidence-based recommendations for evaluation, referral, and management are provided to help guide clinicians in the care of $3 q 29$ deletion patients.

Genetics in Medicine (2021) 23:872-880; https://doi.org/10.1038/s41436-020-01053-1

\section{INTRODUCTION}

Individuals with 3q29 deletion syndrome (OMIM 609425) are hemizygous for a $1.6-\mathrm{Mb}$ interval containing 21 protein coding genes. ${ }^{1}$ The syndrome (prevalence $\sim 1$ in 30,000 ) is associated with reduced birth weight, failure to thrive, heart defects, intellectual disability, anxiety disorder, autism spectrum disorder, and schizophrenia. ${ }^{1-6}$ Case reports have provided a rich source of data on individual patients (reviewed $\mathrm{in}^{2}$ ). However, phenotyping in case reports is not systematic, and can lead to bias in the curation of associated symptoms. ${ }^{2}$ Large cohorts of de-identified individuals ascertained for a specific phenotype (such as schizophrenia ${ }^{5}$ ) provide evidence of increased risk for a single manifestation, but do not inform about the broader phenotypic spectrum. Systematic self-report of phenotypes from registries are emerging but are hampered by limitations of self-reported data. ${ }^{3,4}$ For these reasons a comprehensive, unbiased characterization of the syndrome is needed. ${ }^{7}$

The present study addresses these knowledge gaps; our clinical team has directly and systematically evaluated 32 study subjects with the canonical 1.6-Mb 3q29 deletion using a standardized phenotyping protocol that includes gold-standard instruments. ${ }^{7}$
These data have revealed new aspects of $3 q 29$ deletion syndrome and provide guidance for the management of patients.

\section{MATERIALS AND METHODS}

Study subject eligibility

The study design has been previously described. ${ }^{7}$ Briefly, individuals were recruited from the 3q29 registry ${ }^{3}$ (3q29deletion.org). Inclusion criteria were validated clinical diagnosis of 3q29 deletion syndrome where the subject's deletion overlapped the canonical region (hg19, chr3:195725000-197350000) by $\geq 80 \%$, and willingness and ability to travel to Atlanta, Georgia. Exclusion criteria were any $3 \mathrm{q} 29$ deletion with less than $80 \%$ overlap with the canonical region, nonfluency in English, and age younger than six years. One exception to the age criterion was made: a 4.85 -year-old who was part of a previously described multiplex family was included in the current study. ${ }^{8}$

\section{Ethics statement}

After informed consent, travel was arranged. Informed consent was received from all participating study subjects. An informed consent session was conducted prior to the study visit, and repeated in-person at the beginning of the study visit.

\footnotetext{
${ }^{1}$ Department of Human Genetics, Emory University School of Medicine, Atlanta, GA, USA. ${ }^{2}$ Department of Pediatrics, Emory University School of Medicine, Atlanta, GA, USA.

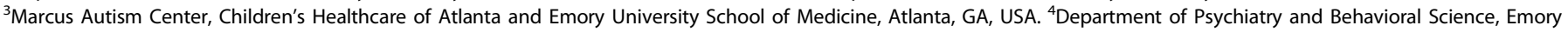

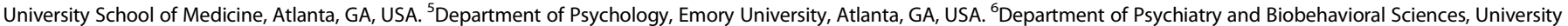

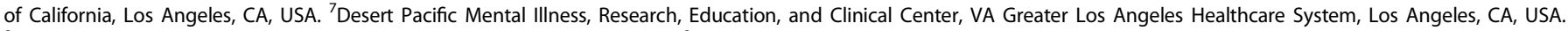

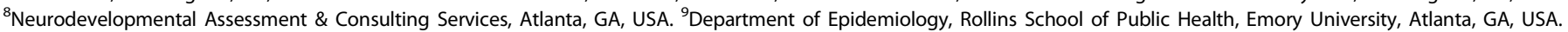

${ }^{11}$ These authors contributed equally: Rossana Sanchez Russo, Michael J. Gambello, Melissa M. Murphy. ${ }^{*} \mathrm{~A}$ list of authors and their affiliations appears at the end of the paper.

凶email: jmulle@emory.edu
} 


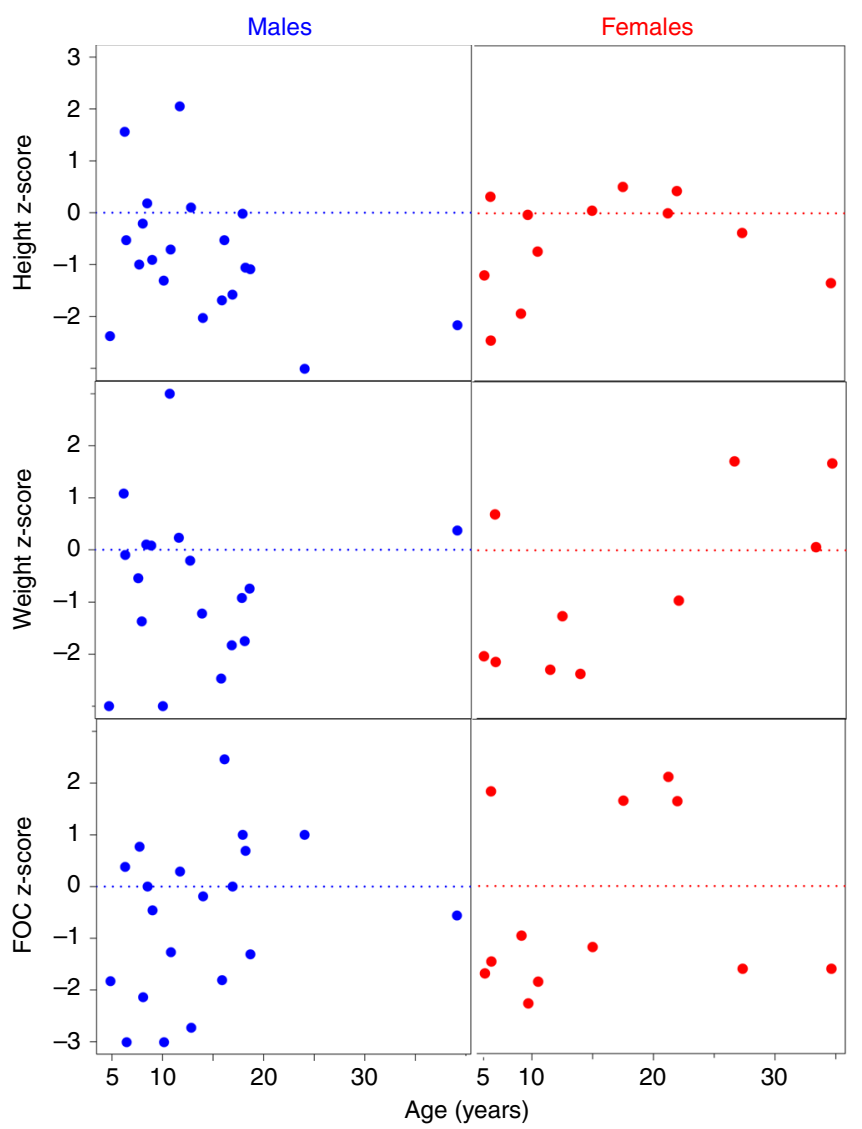

Fig. 1 Z-scores for height, weight, and frontal occipital circumference (FOC) as a function of age, for males (blue, left panels) and females (red, right panels). These data indicate the 3q29 deletion has an impact toward diminished height, weight, and FOC, and this is more pronounced at younger ages.

\section{Evaluations}

All study subjects were evaluated over two days. Subjects were directed to take medications as they normally would. Evaluations were conducted as described in the following sections (summarized in Table S1).

Medical history and physical examination. Parents completed a comprehensive medical history (Supplementary Materials), reviewed during the visit with a medical geneticist (E.B., R.S.R., M.J.G.), who also completed a physical examination of the study subject. Following study visits, the medical geneticists met to identify relevant characteristics by system and classify characteristcs using Human Phenotype Ontology (HPO) terminology (https://hpo.jax.org/app/). Assessment of craniofacial features is reported elsewhere. ${ }^{9}$ Z-scores and percentiles for height, weight, and head circumference were determined according to The Handbook of Physical Measurements. ${ }^{10}$ Four study subjects taking antipsychotic medications reported rapid weight gain upon antipsychotic use; these individuals were excluded from the weight analysis in Fig. 1.

Neurodevelopmental evaluation. The systematic battery included goldstandard instruments for assessment of cognitive ability, adaptive behavior, visual-motor integration (VMI), autism spectrum disorder, and executive function (Table S1). Cognitive testing, VMI, and autism assessments were carried out by clinical psychologists (C.A.S., C.K., S.P.W.) early in the day to reduce fatigue. Adaptive behavior and executive function instruments were completed by the parent or caretaker electronically via publisher websites (Pearson Q-global and PARiconnect, respectively) either before or during the visit.

Psychiatric evaluation. Instruments were deployed to assess anxiety, general psychopathology, and schizophrenia prodrome/psychosis. Psychosis and prodromal psychosis were evaluated in individuals age 8 years and older $(n=21)$; at younger ages, developmentally appropriate magical thinking cannot be distinguished from true psychosis. All instruments were administered by trained personnel. A qualitative assessment of global mental status was conducted by team psychiatrists (J.F.C., M.T.E.) to supplement results from formal assessments.

Neuroimaging. Magnetic resonance imaging (MRI) data were collected from a subset of study subjects $(n=24)$ on a Siemens Magnetom Prisma 3T scanner at the Center for Systems Imaging Core using a 32-channel head coil. T1-weighted and T2-weighted high-resolution structural images were acquired. Specific details of the image acquisition parameters are provided in supplemental methods. Of the eight subjects who did not complete the MRI, two were at too low a developmental level to successfully complete the procedure, one declined to participate, and five were medically ineligible.

Neurological exam. A subset of study subjects $(n=23)$ were evaluated by a pediatric neurologist (S.K.) for gross and fine motor phenotypes, including assessment of gait, heel to toe and stressed gait, fine finger movements, rapid alternating movements, as well as finger to nose and heel to shin tests. Performance on each task was rated using a 4-point scale of impairment severity: 0 (none/normal), 1 (mild), 2 (moderate), and 3 (severe). Of the study subjects who did not have a neurology exam, nine joined the study before neurology assessment was added to the protocol. For four study subjects, the neurologist was unavailable during the study visit.

\section{RESULTS}

Participants

Thirty-two participants were consented and evaluated, including four participants from a single family. ${ }^{8}$ Study subjects ranged in age from 4.8 to 39.1 years (mean age 14.5 years, median age 11.7 years); $62.5 \%(n=20)$ were male (Table 1$)$.

\section{Medical history results}

A summary of characteristics reported in at least $10 \%$ of study subjects is presented in Table 1. Supplemental Table S2 includes characteristics reported in at least one study subject. The medical history review did not reveal prenatal/perinatal findings that were generalizable across subjects.

\section{Ear, nose, and throat (ENT)}

Seventy-eight percent of study subjects $(n=25)$ had an ENTrelated symptom or diagnosis in their medical history. Twenty-two percent $(n=7)$ had recurrent ear infections, and three subjects required surgery. Fifty-nine percent $(n=19)$ had a symptom or diagnosis related to the eye. The most common ocular phenotype was strabismus $(28 \%, n=9)$, with three subjects requiring surgery. Vision problems encountered later in childhood included astigmatism $(16 \%, n=5)$ and myopia $(16 \%, n=5)$. Epistaxis was the most common nasal manifestation occurring in $22 \%(n=7)$; two subjects required surgical correction. Dental anomalies were reported in $41 \% \quad(n=13)$ and commonly included enamel hypoplasia with proclivity to caries and abnormalities in number (hyperdontia and hypodontia) and size of teeth.

\section{Cardiovascular}

Structural cardiovascular disease was reported in $47 \%(n=15)$. These included complex congenital cardiovascular disease $(25 \%$, $n=8)$ such as hypoplastic right heart $(n=1)$, patent ductus arteriosus (PDA; $n=2)$, pulmonary atresia $(n=2)$, pulmonary stenosis $(n=1)$, tricuspid stenosis $(n=1)$, ventricular septal defect $(n=2)$, and arterial-venous malformation (AVM) originating from the descending thoracic aorta $(n=1)$. In 4 subjects $(12.5 \%)$ surgery was required to address the cardiovascular condition. 
874

Table 1. Participant demographic information, neurodevelopmental assessment scores, frequency of symptoms, diagnoses, and physical exam findings reported in $10 \%$ or more of cases $(N=32)$.

\begin{tabular}{|c|c|c|}
\hline Descriptive characteristics & Mean (SD) & Range \\
\hline Age in years & $14.5(8.26)$ & 4.85-39.12 \\
\hline Sex & $n$ & $\%$ \\
\hline Female & 12 & $37 \%$ \\
\hline Male & 20 & $63 \%$ \\
\hline Ethnicity & $n$ & $\%$ \\
\hline Non-Hispanic & 31 & $97 \%$ \\
\hline Race & $n$ & $\%$ \\
\hline White & 29 & $91 \%$ \\
\hline More than 1 race & 3 & $9 \%$ \\
\hline $\begin{array}{l}\text { Parent-reported symptoms/diagnoses } \\
\text { with associated procedure or } \\
\text { intervention }\end{array}$ & $n$ & $\%$ \\
\hline General & 7 & $22 \%$ \\
\hline Fatigue & 7 & $22 \%$ \\
\hline HEENT & 25 & $78 \%$ \\
\hline $\begin{array}{l}\text { Recurrent Infection addressed with } \\
\text { surgery (any) }\end{array}$ & 6 & - \\
\hline Cases requiring tonsillectomy & 4 & - \\
\hline Cases requiring adenoidectomy & 5 & - \\
\hline Eye (any) & 19 & $59 \%$ \\
\hline Astigmatism & 5 & $16 \%$ \\
\hline Myopia & 5 & $16 \%$ \\
\hline Strabismus & 9 & $28 \%$ \\
\hline $\begin{array}{l}\text { Cases with strabismus requiring } \\
\text { surgery }\end{array}$ & 3 & - \\
\hline Ear (any) & 7 & $22 \%$ \\
\hline Recurrent ear infection & 7 & $22 \%$ \\
\hline $\begin{array}{l}\text { Cases requiring myringotomy and tube } \\
\text { placement }\end{array}$ & 3 & - \\
\hline Nose (any) & 8 & $25 \%$ \\
\hline Epistaxis & 7 & $22 \%$ \\
\hline Cases with epistaxis requiring surgery & 2 & - \\
\hline Teeth (any) & 13 & $41 \%$ \\
\hline Abnormal number or size of teeth & 5 & $16 \%$ \\
\hline Abnormal dentition & 9 & $28 \%$ \\
\hline Cardiovascular & 16 & $50 \%$ \\
\hline Structural & 15 & $47 \%$ \\
\hline Murmur & 7 & $22 \%$ \\
\hline $\begin{array}{l}\text { Complex congenital cardiovascular } \\
\text { disease }\end{array}$ & 8 & $25 \%$ \\
\hline Cases requiring surgery & 4 & - \\
\hline Respiratory & 8 & $25 \%$ \\
\hline Asthma & 6 & $19 \%$ \\
\hline Sleep & 10 & $31 \%$ \\
\hline Sleep disturbance & 10 & $31 \%$ \\
\hline Gastrointestinal & 26 & $81 \%$ \\
\hline Feeding problems beyond infancy & 5 & $16 \%$ \\
\hline Failure to thrive beyond infancy & 13 & $41 \%$ \\
\hline Constipation & 13 & $41 \%$ \\
\hline
\end{tabular}

\begin{tabular}{|c|c|c|}
\hline $\begin{array}{l}\text { Parent-reported symptoms/diagnoses } \\
\text { with associated procedure or } \\
\text { intervention }\end{array}$ & $n$ & $\%$ \\
\hline Reflux & 16 & $50 \%$ \\
\hline Feeding problems in infancy & 19 & $59 \%$ \\
\hline Renal/genitourinary & 9 & $28 \%$ \\
\hline Enuresis & 7 & $22 \%$ \\
\hline Integumentary/dermatologic & 11 & $34 \%$ \\
\hline Eczema & 4 & $13 \%$ \\
\hline Keratosis pilaris & 4 & $13 \%$ \\
\hline Allergy/immunology & 9 & $28 \%$ \\
\hline Food allergy & 4 & $13 \%$ \\
\hline Seasonal allergies & 5 & $16 \%$ \\
\hline Neurological (any) & 18 & $56 \%$ \\
\hline $\begin{array}{l}\text { Seizures (e.g., atonic, febrile, } \\
\text { nocturnal) }\end{array}$ & 4 & $13 \%$ \\
\hline Headache or migraine & 5 & $16 \%$ \\
\hline \multicolumn{3}{|l|}{ Physical exam findings } \\
\hline Musculoskeletal (any) & 27 & $84 \%$ \\
\hline Axial (any) & 15 & $47 \%$ \\
\hline $\begin{array}{l}\text { Chest deformities (e.g., chest } \\
\text { asymmetry, pectus carinatum, } \\
\text { pectus excavatum) }\end{array}$ & 13 & $41 \%$ \\
\hline Extremity-upper (any) & 15 & $47 \%$ \\
\hline Tapered finger & 4 & $13 \%$ \\
\hline Long, thin finger & 8 & $25 \%$ \\
\hline Extremity-lower (any) & 23 & $72 \%$ \\
\hline $\begin{array}{l}\text { Abnormal toes (e.g., hallux valgus, } \\
\text { big or broad hallux, overlapping or } \\
\text { curved toes) }\end{array}$ & 9 & $28 \%$ \\
\hline Medial rotation medial malleolus & 10 & $31 \%$ \\
\hline Pes planus & 10 & $31 \%$ \\
\hline $\begin{array}{l}\text { Neurodevelopmental assessment } \\
\text { findings }\end{array}$ & Mean/median & Range \\
\hline \multicolumn{3}{|l|}{ Domain } \\
\hline $\begin{array}{l}\text { Cognitive, standard score (GCA or } \\
\text { FSIQ) }\end{array}$ & $73.0 / 75.5$ & $99-40$ \\
\hline Adaptive behavior, standard score & $73.9 / 70.5$ & $48-110$ \\
\hline Executive function, $t$-score & $68.3 / 69.0$ & $45-88$ \\
\hline $\begin{array}{l}\text { Visual-motor integration, } \\
\text { standard score }\end{array}$ & $69.5 / 67$ & $45-103$ \\
\hline \multicolumn{3}{|c|}{$\begin{array}{l}\text { HEENT Head, Eyes, Ears, Nose and Throat, GCA General Conceptual Ability, } \\
\text { FSIQ Full-scale IQ. } \\
\text { Of the six recurrent infection cases addressed with surgery, four of those } \\
\text { were cases requiring tonsillectomy and five were cases requiring } \\
\text { adenoidectomy. } \\
\text { Numbers in bold represent a count of any instance in the category for each } \\
\text { case (total possible }=32 \text { ); standard scores have an expected population } \\
\text { mean of } 100 \text { and a standard deviation of } 15 \text {; scores below } 70 \text { ( } 2 \text { SD from the } \\
\text { expected mean) are considered to denote a clinically significant weakness, } \\
t \text {-scores have an expected population mean of } 50 \text { and SD of } 10 \text {; scores } \\
\text { above } 70 \text { ( } 2 \text { SD from the expected mean) are considered to denote a } \\
\text { clinically significant weakness. }\end{array}$} \\
\hline
\end{tabular}


Gastrointestinal

Gastrointestinal manifestations were noted in the majority $(81 \%$, $n=26)$ of subjects. Half $(50 \%, n=16)$ reported gastroesophageal reflux and $41 \%(n=13)$ had chronic constipation. Additionally, feeding difficulties in infancy were reported in more than half $(59 \%, n=19)$ and persisted beyond infancy in $16 \%(n=5)$. Only $9 \%(n=3)$ of participants had failure to thrive in infancy, two of whom continued to have failure to thrive beyond infancy. In contrast, failure to thrive beyond infancy was reported in $41 \%$ $(n=13)$ of the overall sample.

\section{Renal/genitourinary}

Enuresis was encountered in $25 \%(n=8)$. Of these, seven had persistent enuresis as measured by the KSADS (Kiddie Schedule for Affective Disorders and Schizophrenia), which was used to assess general psychopathology including enuresis. The remaining individual had a history of enuresis reported by parents during the medical history interview that was resolved at the time of this study.

Respiratory, allergy, and immunological

Asthma was the most common respiratory manifestation, occurring in 19\% $(n=6)$. Seasonal allergies were reported in $16 \%(n=5)$, two of whom also had asthma. Food allergies were noted in $13 \%(n=4)$.

\section{Integumentary}

Thirteen percent $(n=4)$ reported eczema. Keratosis pilaris was also reported in $13 \%(n=4)$.

\section{Sleep}

Sleep disturbances were reported in at least $31 \%(n=10)$, including difficulty initiating sleep $(n=5)$, maintaining sleep $(n=6)$, and sleep walking $(n=1)$.

\section{Neurological}

Seizures were reported in $13 \%(n=4)$. Sixteen percent $(n=5)$ reported experiencing headaches.

Physical examination. Physical findings present in $10 \%(n=4$ or more) of participants are summarized in Table 1. Supplemental Table S3 incudes characteristics found in at least one participant.

\section{Growth parameters}

Individuals with the $3 q 29$ deletion have growth parameters that are on average lower than expected age and sex norms (Fig. 1). The average $z$-score for height, weight, and head circumference (frontal occipital circumference; FOC) is $-0.72,-0.63$, and -0.54 , respectively. Twenty-five percent of subjects $(n=8)$ had a weight -2 SD below the mean. These subjects ranged from 4 to 24 years. Sixteen percent of subjects $(n=5)$ were -2 SD below the mean for height. Sixteen percent $(n=5)$ were -2 SD below the mean for head circumference. Notably, most subjects had low measurements in only one parameter; no subject had a low measurement for all three parameters.

\section{Musculoskeletal manifestations}

Eighty-four percent $(n=27)$ had one or more musculoskeletal phenotypes. Chest deformities were noted in $41 \%(n=13)$, and included pectus excavatum $(25 \%, n=8)$, pectus carinatum $(9 \%$, $n=3)$, and chest asymmetry $(6 \%, n=2)$. Manifestations in the upper extremities were seen in $47 \%(n=15)$. The most common findings were long, thin fingers $(22 \%, n=7)$ and tapered fingers $(13 \%, n=4)$. Lower extremity manifestations were seen in $72 \%$

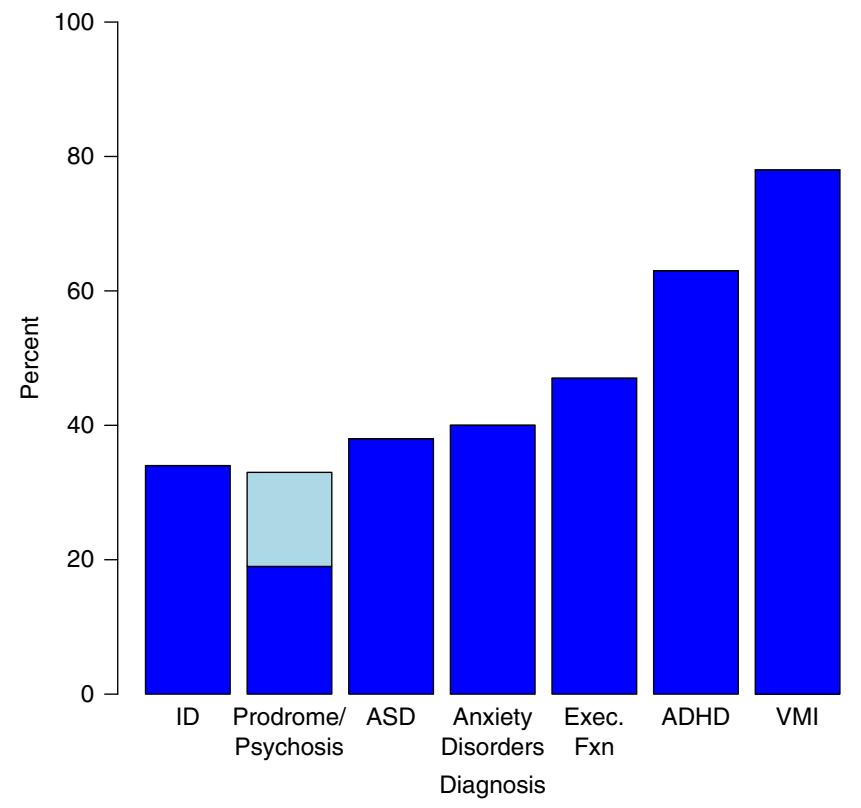

Fig. 2 Percent of 3q29 deletion participants who qualify for neurodevelopmental and neuropsychiatric diagnoses after direct evaluation by our team. $19 \%$ of study subjects qualified for a diagnosis of psychosis; $14 \%$ had features of schizophrenia prodrome (light blue). ADHD attention deficit-hyperactivity disorder, ASD autism spectrum disorder, ID intellectual disability, VMI graphomotor weakness.

$(n=23)$. These included pes planus $(31 \%, n=10)$ or medial rotation of medial malleolus $(31 \%, n=10)$, with $22 \%$ having both pes planus and medial rotation of the medial malleolus. Abnormalities of the toes were also observed in $28 \%(n=9)$, including abnormal hallux $(13 \%, n=4)$ commonly seen as broad hallux and hallux valgus, and abnormal nonhallux toes (19\%, $n=$ 6) frequently seen as curved, short, or overlapping toes.

Within the other systems (see Supplemental Table S3), no single finding was generalizable across study subjects.

Neurodevelopmental phenotypes. Rates of neurodevelopmental diagnoses are shown in Fig. 2; mean and median scores with ranges are shown in Table 1.

Cognitive and adaptive behavior profiles

The average cognitive ability measure was 73.0 (median 75.5, range 40-99). The average adaptive behavior standard score was 73.9 (median 70.1, range 48-107). Individuals were considered to have intellectual disability (ID) if both cognitive and adaptive behavior scores were $\geq 2$ SD below the expected mean ( $\leq 70$ on both evaluations). By this metric, 11 individuals (34\%) qualified for a diagnosis of ID, a 31-fold increase over the expected population prevalence of $1.1 \%{ }^{11}$ Graphomotor weakness: $78 \%$ were found to have clinically significant visual-motor integration weakness, defined as a standard score $>2$ SD below the expected mean on the VMI-6. Executive function: $47 \%(n=15)$ were found to have clinically significant deficits in executive functioning skills, with $t$ scores that were $\geq 2 \mathrm{SD}$ above the mean. Autism spectrum disorder (ASD): Autism symptomatology was assessed using the ADOS-2 (Autism Diagnostic Observation Schedule) and ADI-R (Autism Diagnostic Interview, Revised); these instruments were used to inform the administering clinician's best estimate diagnosis. Of 32 individuals evaluated, 12 (37.5\%) met Diagnostic and Statistical Manual of Mental Disorders V (DSM-V) criteria for an ASD diagnosis. Nine of 20 males evaluated (45\%) qualified for ASD, a 15-fold excess compared with the general male population prevalence of 


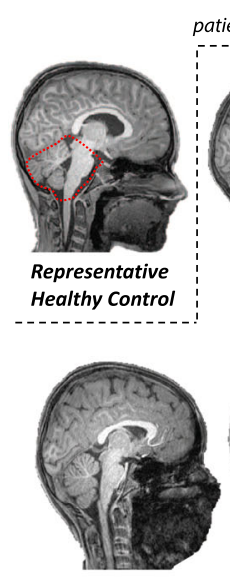

9 y/o female

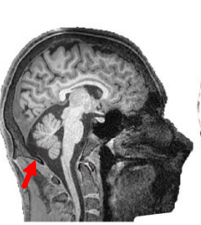

17 y/o male patients with 3q29del (in ascending order of age)

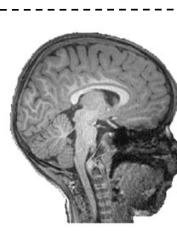

4 y/o male

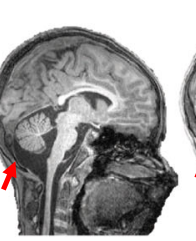

10 y/o male

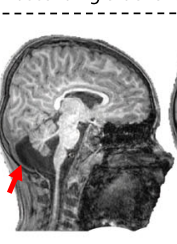

6 y/o male

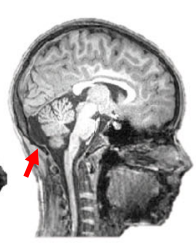

$10 \mathrm{y} / \mathrm{o}$ female

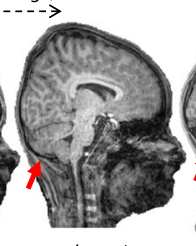

6 y/o male

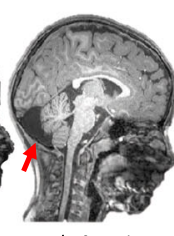

6 y/o female

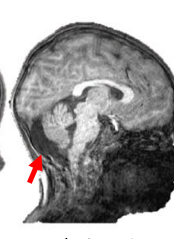

6 y/o female

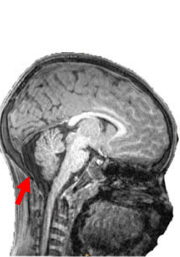

7 y/o male

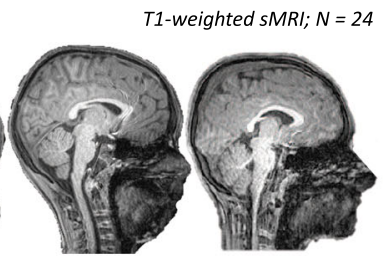

8 y/o male

8 y/o male

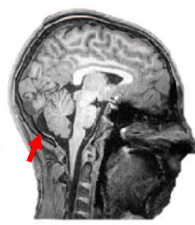

12 y/o male

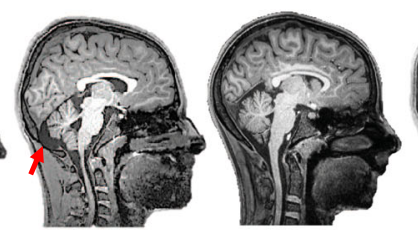

15 y/o female

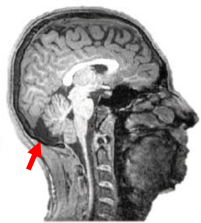

15 y/o male

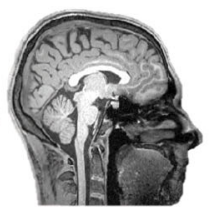

16 y/o male

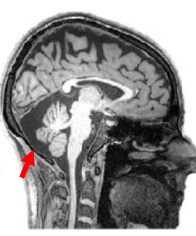

21 y/o female

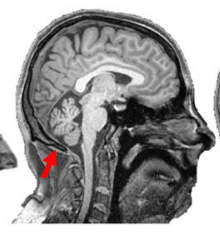

21 y/o female

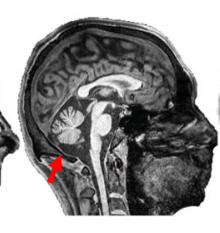

24 y/o male

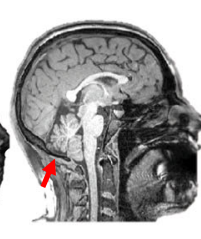

27 y/o female

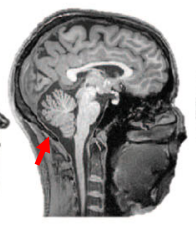

34 y/o female

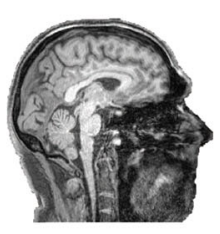

39 y/o male

Fig. 3 Midsagittal T1-weighted images acquired from $\mathbf{N}=\mathbf{2 4}$ patients with 3q29 deletion (3q29Del) syndrome. A representative T1weighted image from a healthy control is provided in the first panel for comparison (red dashed lines indicate normative anatomical boundaries of the posterior fossa). T1-weighted patient images are displayed in ascending chronological age, with participant demographics (sex, age in years) provided below each scan. Posterior fossa abnormalities (indicated by red arrows) were observed in $N=17$ (70.83\%) patients. Note that midline sagittal images were selected to provide optimal visualization of the cerebellar vermis and retrocerebellar arachnoid cysts. Presence of cerebellar hemispheric hypoplasia was determined via anatomical inspection of the adjacent cerebellar hemispheres in the coronal and horizontal planes, which were not included in this figure due to space limitations.

1 in 33 (3.0\%). ${ }^{12}$ Three of 12 females evaluated (25\%) were diagnosed with ASD, a 36 -fold excess compared with the general population rate of ASD in females (1 in 144, 0.7\%). ${ }^{12}$ These data confirm a higher risk for ASD associated with the $3 q 29$ deletion in both males and females.

\section{Psychiatric evaluation}

Anxiety disorders: $40 \%(n=13)$ had at least one anxiety disorder; $18 \%(n=6)$ had more than one anxiety disorder diagnosis. Anxiety disorders included generalized anxiety disorder $(22 \%, n=$ $7)$, specific phobia $(19 \%, n=6)$, separation anxiety $(12.5 \%, n=4)$, and social anxiety disorder $(6 \%, n=2)$. Prodromal symptoms and psychosis: of 21 individuals who were evaluated, 19\% $(n=4)$ qualified for diagnosis of a psychotic disorder. This is 25 times higher than expected, given the population prevalence of psychotic disorders in general, ${ }^{13}$ and 67 times higher than expected given the population prevalence of schizophrenia specifically. ${ }^{14}$ Three additional individuals (14\%) were found to exhibit features consistent with the psychosis prodrome. These data are consistent with prior reports identifying the 3q29 deletion as a risk factor for schizophrenia. ${ }^{5,6,15-17}$ General psychopathology: 63\% $(n=20)$ qualified for a diagnosis of attention deficit-hyperactivity disorder (ADHD), 6.9 times more than the estimated population prevalence of $9.04 \% .^{11}$ These individuals could be further classified into subtypes: ADHDinattentive type $(n=10)$, ADHD combined type $(n=8)$, and ADHD hyperactive/impulsive $(n=1)$. One additional individual did not meet criteria for any subtype and was diagnosed as "other specified ADHD." The high rate of ADHD in 3q29 deletion study subjects is consistent with deficits in executive function, as reported above. No other psychiatric diagnosis was present in greater than $10 \%$ of study subjects.
Neuroimaging

Inspection of T1- and T2-weighted images by a pediatric neurologist (S.K.) revealed abnormalities of the posterior fossa in $70.83 \%$ of the individuals who completed an MRI scan (Fig. 3, Table S4; 5 subjects had $>1$ posterior fossa abnormality). Cerebellar vermis hypoplasia was observed most frequently $(n=8,33.33 \%)$, followed by retrocerebellar arachnoid cysts $(n=$ $7,29.17 \%)$, cerebellar hemispheric hypoplasia $(n=6,25.0 \%)$, and global cerebellar hypoplasia ( $n=1,4.17 \%$ ). It is currently unknown whether the observed cerebellar phenotypes reflect a progressive course of atrophy; longitudinal measurements should be obtained in follow-up studies to make this distinction. Posterior fossa abnormalities were observed in both young (age 6) and older (age 34) subjects and in both males and females (Supplemental Table S5), suggesting that these abnormalities are a distinctive feature of the 3q29 deletion syndrome. At present, the pathogenesis and developmental outcomes associated with these abnormalities are unclear; abnormalities can arise from inherited (genetic) or acquired (disruptive) causes, and have been implicated in multiple genetic syndromes. ${ }^{18,19}$

Neurological examination

In light of the posterior fossa abnormalities identified in T1- and T2-weighted images, a subset of study subjects $(n=23)$ were evaluated by a pediatric neurologist for motor phenotypes associated with cerebellar dysfunction. Motor phenotypes were identified, but generally were mild or moderate (Table S6). Only one person displayed a severe cerebellar motor phenotype (rapid alternating movement). These data suggest that the posterior fossa abnormalities do not result in gross or severe motor phenotypes. 
Table 2. Summary of recommendations.

\begin{tabular}{|c|c|c|c|}
\hline System & Evaluation & When & Management and recommendations \\
\hline Ocular & Follow-up with ophthalmologist & At diagnosis & $\begin{array}{l}\text {-Vision screening to monitor for refractive errors } \\
\text { and strabismus } \\
\text { - Strabismus may require patching or surgery }\end{array}$ \\
\hline Ears, nose, throat (ENT) & Follow-up with otolaryngology (ENT) & As needed & $\begin{array}{l}\text { - Hearing screening } \\
\text { - Monitoring recurrent ear infections and epistaxis } \\
\text { - Standard surgical management as required }\end{array}$ \\
\hline Dental & $\begin{array}{l}\text { Ongoing follow-up with dentist for } \\
\text { abnormal enamel, tooth shape, } \\
\text { and number }\end{array}$ & Ongoing & $\begin{array}{l}\text { - Initial pediatric dental evaluation by } 1 \text { year of age } \\
\text { - May need increased frequency of checkups and } \\
\text { cleanings } \\
\text { - Dental care may require assistance with daily } \\
\text { brushing and flossing }\end{array}$ \\
\hline Cardiovascular & Evaluation by cardiologist & At diagnosis & $\begin{array}{l}\text { - Echocardiogram } \\
\text { - Evaluation in infancy for evidence of congenital } \\
\text { cardiovascular disease } \\
\text { - Referral to cardiologist and/or cardiothoracic } \\
\text { surgeon as needed }\end{array}$ \\
\hline Gastrointestinal & $\begin{array}{l}\text { Consider referral to gastroenterologist } \\
\text { and/or feeding specialist or nutritionist }\end{array}$ & As needed & $\begin{array}{l}\text { - Consider evaluation for feeding and growth as } \\
\text { indicated } \\
\text { - Behavioral and/or medical treatment of } \\
\text { constipation, if persistent } \\
\text { - Age-specific treatment for reflux, including testing } \\
\text { for food allergies }\end{array}$ \\
\hline Renal & Follow-up with urologist & As needed & $\begin{array}{l}\text { - Consider evaluation for enuresis, if persistent } \\
\text { - Consider behavioral interventions, including alarm } \\
\text { techniques, if indicated } \\
\text { - May require evaluation of medications that could } \\
\text { contribute to enuresis }\end{array}$ \\
\hline Musculoskeletal & Referral to orthopedist as needed & As needed & $\begin{array}{l}\text { - Evaluation for chest anomalies and flat feet } \\
\text { - Routine screening for scoliosis }\end{array}$ \\
\hline Pulmonary and sleep & $\begin{array}{l}\text { Referral to pulmonologist/sleep clinic, } \\
\text { as needed }\end{array}$ & As needed & $\begin{array}{l}\text { - Sleep study, as needed } \\
\text { - Recommendations for implementing healthy } \\
\text { sleep hygiene habits } \\
\text { - Management of sleep disturbance, as needed }\end{array}$ \\
\hline Allergy and immunology & Referral to specialist as needed & As needed & $\begin{array}{l}\text { - Allergy testing, as needed } \\
\text { - Standard management for asthma, allergies, } \\
\text { and eczema } \\
\text { - Assess for food allergies }\end{array}$ \\
\hline Neurological & Referral to neurologist, as needed & $\begin{array}{l}\text { At diagnosis and } \\
\text { ongoing }\end{array}$ & $\begin{array}{l}\text { - Evaluation for seizures, if indicated } \\
\text { - Evaluation of muscle tone, if indicated }\end{array}$ \\
\hline Neurodevelopmental & $\begin{array}{l}\text { Referral to developmental pediatrician } \\
\text { and/or clinical psychologist }\end{array}$ & $\begin{array}{l}\text { Follow-up } \\
\text { throughout early } \\
\text { childhood }\end{array}$ & $\begin{array}{l}\text { - Evaluation for autism spectrum disorder, cognitive } \\
\text { ability, executive function deficits } \\
\text { - Evaluation for developmental needs and early } \\
\text { intervention (e.g., physical therapy, } \\
\text { speech-language therapy, cognitive behavioral } \\
\text { therapy for social skills training) } \\
\text { - Evaluation of fine motor function and intervention } \\
\text { (e.g., occupational therapy) } \\
\text { - Adaptive behavior (e.g., social skills training) }\end{array}$ \\
\hline Psychiatric & Referral to child/adult psychiatrist & $\begin{array}{l}\text { Childhood to } \\
\text { early adult }\end{array}$ & $\begin{array}{l}\text { - Periodic evaluation for anxiety disorders, attention } \\
\text { deficit hyperactivity disorder, emerging features of } \\
\text { prodrome/psychosis } \\
\text { - Cognitive behavioral therapy for anxiety } \\
\text { - Medications for anxiety, attention } \\
\text { deficit-hyperactivity disorder (ADHD), psychosis } \\
\text { may be indicated }\end{array}$ \\
\hline
\end{tabular}

\section{DISCUSSION}

Here we report comprehensive descriptions of $3 q 29$ deletion syndrome, by direct systematic evaluation of 32 study subjects using a defined protocol and gold-standard instruments. While nearly all major systems are affected, the ocular, dental, cardiovascular, gastrointestinal, renal, musculoskeletal, and neurologic systems should be prioritized for evaluation and follow-up.
There is also a significant burden of neurodevelopmental and neuropsychiatric illness, requiring intervention and support across the lifespan. Our findings suggest recommendations for clinical care, described in detail below and summarized in Table 2.

Almost $60 \%$ of subjects reported ocular manifestations; the most frequent were strabismus and refractive errors, including myopia and astigmatism. In some cases, the strabismus required 
surgical repair. The high rate of ocular manifestations is consistent with previous reports ${ }^{2}$ and suggests the importance of evaluation by a pediatric ophthalmologist as early as possible for evaluation of refractive errors and strabismus. If detected early, these manifestations benefit from treatment or corrective interventions to prevent long term sequelae.

Similar to prior reports, ${ }^{2,3,20}$ recurrent ear infections were common and sometimes required myringotomy tubes. Epistaxis has not been previously reported but was commonly seen in over $20 \%$ of subjects without a concurrent history of nose picking. Two of the seven cases required surgery, one of which had developed anemia. The high rates of ear infections and epistaxis suggest a low threshold for involving otolaryngology specialists in care. When taken together with increased risk for speech-language disorders, these results further highlight the importance of hearing screening to monitor for conductive hearing loss and associated disruptions to speech-language development.

Consistent with reports of dental anomalies in the literature, ${ }^{2,3,20}$ parental report revealed that $41 \%$ of study subjects manifest a broad spectrum of dental anomalies, such as abnormal tooth shape, size, and number; diastema; enamel hypoplasia; and frequent cavities. In some cases, extensive surgical intervention was required, including up to five root canals in a single individual. Cavities occurred despite good oral hygiene. Notably, our study and others ${ }^{2,3}$ report dental anomalies along with gastroesophageal reflux, which may contribute to dental problems. The high frequency of dental problems among individuals with 3q29 deletion highlights the need for early and ongoing dental care.

Previous literature reported elevated rates of heart defects in individuals with $3 q 29$ deletion.,3,21 Our findings confirm this increased risk. Structural cardiovascular manifestations were reported in almost half of subjects, and almost all of were heart defects ranging in severity from PDA to hypoplastic right heart syndrome. No single common congenital heart defect was observed. Half of subjects with a cardiovascular manifestation required surgical repair, suggesting the need for echocardiogram at diagnosis.

Gastrointestinal manifestations occurred in $81 \%$ of subjects and are noted as early as infancy. Feeding difficulties in infancy, manifesting as problems with latching, were sometimes associated with failure to gain weight and were common presenting signs. Feeding difficulties, coupled with reflux and constipation, and less frequently, dysphagia and esophageal dysmotility, persisted beyond infancy. Three subjects needed gastrostomy tubes beyond infancy due to restrictive food preferences and failure to thrive. In a separate analysis, we have documented increased symptoms of pediatric feeding disorders among individuals with $3 q 29$ deletion syndrome (unpublished data, https://doi.org/10.1101/2020.09.18.20197301). Future studies are required to understand if feeding problems lead to caloric and nutritional deficiencies and may therefore contribute to the observed smaller height and lower weight as documented in growth parameters and/or whether these subjects are constitutionally smaller.

Occurring in $22 \%$ of subjects, enuresis was the most common renal/genitourinary manifestation reported. The subjects with a diagnosis of enuresis ranged in age from 6 to 16.9 years, suggesting that enuresis continues beyond the age in which it often resolves spontaneously. Enuresis is typically diagnosed more commonly among males than females in the general population. ${ }^{22}$ However, this sex difference was not apparent among our subjects, four of whom were male and three of whom were female, which supports the notion that the 3q29 deletion contributes to enuresis. Indeed, prior case studies report a 15year-old male ${ }^{2}$ and an 8-year-old female ${ }^{23}$ with urinary voiding dysfunction. Although varied by age and gender, the frequency of enuresis is reported to be $2.8 \%$ for children ages $6-14$ years in the general population, indicating an approximately ninefold enrichment among our study subjects and may require behavioral or pharmacological intervention.

Although not previously described in the literature, a constellation of respiratory, allergy, and immunological symptoms were reported among study subjects. Asthma was reported by $19 \%$ of our study subjects, which is higher than the frequency of $10 \%$ in the general population of developed Western countries. ${ }^{24,25}$ Food allergies were reported in $13 \%$ of subjects, which is almost double the $6.7 \%$ of food allergies in the general population. ${ }^{26}$ Seasonal allergies were reported by $16 \%$ of study subjects. Although the rates of seasonal allergy did not exceed the rate of $10-20 \%$ in the general population, ${ }^{27}$ these results suggest a tendency to atopy. Moreover, common skin manifestations reported among study subjects included eczema and keratosis pilaris, both of which are also associated with atopy. Early evaluation and routine follow-up with a pediatric pulmonologist or allergist may be important for ongoing care.

This study identifies significant abnormalities in sleep in $31 \%$ of subjects. Sleep abnormalities ranged from difficulty initiating or maintaining sleep to reporting sleep walking and sleep apnea. Sleep disturbances can co-occur with other diagnoses, such as enuresis. ${ }^{28,29}$ Indeed, half of the subjects in our cohort with enuresis also had an additional sleep disturbance. Diagnosis and management of sleep disorders, particularly among subjects with other comorbidities, may lead to improvement in multiple areas.

The present study documented musculoskeletal anomalies in the majority $(84 \%)$ of cases. Upon closer examination, chest deformities were seen in $41 \%$ of subjects with the majority having pectus excavatum or pectus carinatum, long and tapered fingers (22\%), and pes planus and hindfoot deformity in 31\% of cases, respectively. These findings are in agreement with those of Cox and Butler. ${ }^{2}$ Based upon the findings documented in the present study, involving orthopedic, podiatric, and/or physical therapy professionals in evaluation and management may be indicated in 3 q29 deletion patients. The high frequency of musculoskeletal findings suggests the need for additional investigation into the effects of the 3q29 deletion on connective tissue. Given the complexity of hereditary connective tissue disorders, their effects on multiple organ systems, and their variable manifestation across the lifespan, additional research with larger samples and targeted assessment of the heart, joints, and skin is warranted.

There is a substantial burden of disability contributed by neurodevelopmental and psychiatric manifestations. Cognitive disability is present but mild to moderate in most of the study subjects we evaluated. However, there is likely a cumulative impact of diminished cognitive ability alongside multiple comorbidities, including ASD, executive functioning deficits, anxiety disorders, and ADHD, that impair overall functioning and impede opportunities for optimal outcome. The high rate of fine motor coordination deficits indicates that graphomotor and other fine motor tasks may be effortful, and these impairments can introduce challenges in academic settings. Occupational therapy and creative classroom accommodations may be helpful to alleviate the burden of writing tasks and may decrease stress in these settings. The high rate of ADHD, anxiety disorders, and psychosis indicate that a child/adolescent psychiatrist should be part of the medical team, with periodic evaluation throughout development to detect emerging symptoms. Because of the risk of psychosis associated with the 3q29 deletion, it is recommended that stimulant use for ADHD be used only cautiously, and with explicit monitoring for emerging psychosis. Medications less likely to drive frank psychotic symptoms (e.g., bupropion, atomoxetine) might be considered as alternatives to amphetamines or methylphenidate.

In the domain of psychiatric symptoms and syndromes, one of the advantages of the study sample is the broad age range of patients. It is well established that the modal age at onset varies 
significantly among diagnostic categories; ASD and ADHD are typically diagnosed early in childhood, whereas mood (depression, anxiety, mania) and psychotic disorders first emerge in adolescence/young adulthood. Thus, it is expected that the rate of the latter disorders in this sample will increase on future diagnostic follow-ups. The broad age range at baseline assessment will enhance opportunities for charting the developmental trajectories of the emergence of a range of psychiatric symptoms/syndromes.

Limitations of this study include the small sample size, though we note that 32 study subjects is relatively robust given the low frequency $(1$ in 30,000$)$ of the syndrome. However, this sample size allows us to describe only the most common manifestations of the syndrome; a larger sample size may reveal additional syndromic features. Because our study required travel to Atlanta, this may have introduced ascertainment bias toward healthier subjects; subjects with behavioral challenges may not have participated. Future directions will include a larger sample size, increased diversity of enrolled study subjects, and longitudinal evaluation. In addition, cross-disorder studies with harmonized evaluations are a priority, to identify shared and unique aspects of the neuropsychiatric profile between $3 q 29$ deletion syndrome and other rare genetic disorders.

In conclusion, many of the medical, neurodevelopmental, and psychiatric findings, although frequent, are nonspecific. Many symptoms noted require medical intervention, but do not necessarily signal the need for genetic testing. As a result, for individuals with $3 q 29$ deletion syndrome, identifying the underlying genetic diagnosis remains a challenge. However, given the constellation of 3q29 deletion syndrome phenotypes, including developmental and neuropsychiatric manifestations, a genetic diagnosis is imperative for developing strategies for effective management. Once 3q29 deletion syndrome is diagnosed, the findings and recommendations in the current study provide clinicians and families a road map for evidence-based care and treatment for individuals with 3q29 deletion syndrome.

\section{DATA AVAILABILITY}

Data collected in this study are deposited in the National Institute of Mental Health (NIMH) data archive (nda.nih.gov) collection 2614 (embargoed until September 2022). Prior to September 2022, data will be made available to qualified investigators upon request.

Received: 27 September 2020; Revised: 20 November 2020; Accepted: 20 November 2020;

Published online: 9 February 2021

\section{REFERENCES}

1. Mulle, J. G., Gambello, M. J., Cook, E. H., Rutkowski, T. P. \& Glassford, M. 3 q29 recurrent deletion. In GeneReviews. (eds Pagon, R. A., Adam, M. P., Ardinger, H. H., Wallace, S. E., Amemiya, A., Bean, L. J. H., Bird, T. D., Ledbetter, N., Mefford, H. C., Smith, R. J. H. \& Stephens, K.) (University of Washington, Seattle, 1993).

2. Cox, D. M. \& Butler, M. G. A clinical case report and literature review of the $3 q 29$ microdeletion syndrome. Clin. Dysmorphol. 24, 89-94 (2015).

3. Glassford, M. R., Rosenfeld, J. A., Freedman, A. A., Zwick, M. E. \& Mulle, J. G.; Unique Rare Chromosome Disorder Support Group. Novel features of 3q29 deletion syndrome: results from the $3 q 29$ registry. Am. J. Med. Genet. A 170, 999-1006 (2016).

4. Pollak, R. M. et al. Neuropsychiatric phenotypes and a distinct constellation of ASD features in 3q29 deletion syndrome: results from the $3 q 29$ registry. Mol. Autism 10, 30 (2019).

5. Marshall, C. R. et al. Contribution of copy number variants to schizophrenia from a genome-wide study of 41,321 subjects. Nat. Genet. 49, 27-35 (2017).

6. Mulle, J. G. The 3 q29 deletion confers $>40$-fold increase in risk for schizophrenia. Mol. Psychiatry 20, 1028-1029 (2015).

7. Murphy, M. M. et al. Study protocol for The Emory $3 q 29$ Project: evaluation of neurodevelopmental, psychiatric, and medical symptoms in 3q29 deletion syndrome. BMC Psychiatry 18, 183 (2018).
8. Murphy, M. M. et al. Comprehensive phenotyping of neuropsychiatric traits in a multiplex 3q29 deletion family: a case report. BMC Psychiatry. 20, 184 (2020).

9. Mak, B. C. et al. Craniofacial features of 3q29 deletion syndrome: application of next generation phenotyping technology. (2020). https://doi.org/10.1101/ 2020.09.18.20197665.

10. Hall, J. G., Allanson, J. E., Gripp, K. W. \& Slavotinek, A. M. Handbook of normal physical measurements. 2nd edn. Oxford: Oxford University Press, 2006.

11. Zablotsky, B. et al. Prevalence and trends of developmental disabilities among children in the United States: 2009-2017. Pediatrics. 144, e20190811 (2019).

12. Maenner, M. J. et al. Prevalence of autism spectrum disorder among children aged 8 years-Autism and Developmental Disabilities Monitoring Network, 11 sites, United States, 2016. MMWR Surveill. Summ. 69, 1-12 (2020).

13. Moreno-Kustner, B., Martin, C. \& Pastor, L. Prevalence of psychotic disorders and its association with methodological issues. A systematic review and metaanalyses. PLoS One 13, e0195687 (2018).

14. Charlson, F. J. et al. Global epidemiology and burden of schizophrenia: findings from the global burden of disease study 2016. Schizophr. Bull. 44, 1195-1203 (2018).

15. Mulle, J. G. et al. Microdeletions of $3 q 29$ confer high risk for schizophrenia. Am. J. Hum. Genet. 87, 229-236 (2010).

16. Levinson, D. F. et al. Copy number variants in schizophrenia: confirmation of five previous findings and new evidence for 3q29 microdeletions and VIPR2 duplications. Am. J. Psychiatry. 168, 302-316 (2011).

17. Szatkiewicz, J. P. et al. Copy number variation in schizophrenia in Sweden. Mol. Psychiatry 19, 762-773 (2014).

18. Aldinger, K. A. et al. Redefining the etiologic landscape of cerebellar malformations. Am. J. Hum. Genet. 105, 606-615 (2019).

19. Bosemani, T. et al. Congenital abnormalities of the posterior fossa. Radiographics. 35, 200-220 (2015).

20. Ballif, B. C. et al. Expanding the clinical phenotype of the $3 q 29$ microdeletion syndrome and characterization of the reciprocal microduplication. Mol. Cytogenet. 1, 8 (2008).

21. Li, F., Lisi, E. C., Wohler, E. S., Hamosh, A. \& Batista, D. A. $3 q 29$ interstitial microdeletion syndrome: an inherited case associated with cardiac defect and normal cognition. Eur. J. Med. Genet. 52, 349-352 (2009).

22. Kiddoo, D. A. Nocturnal enuresis. CMAJ. 184, 908-911 (2012).

23. Dasouki, M. J., Lushington, G. H., Hovanes, K., Casey, J. \& Gorre, M. The 3q29 microdeletion syndrome: report of three new unrelated patients and in silico "RNA binding" analysis of the 3q29 region. Am. J. Med. Genet. A. 155A, 1654-1660 (2011).

24. Bousquet, J., Bousquet, P. J., Godard, P. \& Daures, J. P. The public health implications of asthma. Bull. World Health Organ. 83, 548-554 (2005).

25. US Centers for Disease Control and Prevention. Asthma surveillance data 2020 https://www.cdc.gov/asthma/asthmadata.htm (2020).

26. Hill, D. A., Grundmeier, R. W., Ram, G. \& Spergel, J. M. The epidemiologic characteristics of healthcare provider-diagnosed eczema, asthma, allergic rhinitis, and food allergy in children: a retrospective cohort study. BMC Pediatr. 16, 133 (2016).

27. Dykewicz, M. S. \& Hamilos, D. L. Rhinitis and sinusitis. J Allergy Clin. Immunol. 125 (2 Suppl 2), S103-S115 (2010).

28. Vasconcelos, M. M. A. et al. Early behavioral risks of childhood and adolescent daytime urinary incontinence and nocturnal enuresis. J. Dev. Behav. Pediatr. 38, 736-742 (2017)

29. Neveus, T. Pathogenesis of enuresis: towards a new understanding. Int. J. Urol. 24 174-182 (2017).

\section{ACKNOWLEDGEMENTS}

We acknowledge the $3 q 29$ study subjects and their families. We also acknowledge the Emory 3q29 Project members. We gratefully acknowledge the Marcus Autism Center for providing clinical assessment resources. Funding for this work was provided by National Institutes of Health $(\mathrm{NIH})$ grants R01 MH110701 and R01 MH118534. REDCap is supported by grant UL1 TR000424.

\section{AUTHOR CONTRIBUTIONS}

Conceptualization: R.S.R., M.J.G., M.M.M., T.L.B., J.F.C., C.K., S.K., L.L., C.A.S., S.S., E.W., J.G. M. Data curation: R.S.R., M.J.G., M.M.M., K.A., E.B., T.L.B., G.C., J.F.C., M.T.E., R.E., K.G., R.M. G., C.K., S.K., E.J.L., L.L., D.M.N., C.A.S., E.S., S.S., E.W., S.P.W., J.G.M. Formal analysis: R.S.R., M.J.G., M.M.M., K.A., T.L.B., R.E., K.G., R.M.G., C.K., S.K., L.L., D.M.N., C.A.S., E.S., S.S., E.W., S. P.W., J.G.M. Funding acquisition: J.G.M., L.L., S.S.; Investigation: R.S.R., M.J.G., M.M.M., K. A., E.B., T.L.B., G.C., J.F.C., M.T.E., R.E., K.G., R.M.G., C.K., S.K., E.J.L., L.L., D.M.N., C.A.S., E.S., S.S., E.W., S.P.W., J.G.M. Methodology: R.S.R., M.J.G., M.M.M., T.L.B., J.F.C., C.K., S.K., L.L., C.A.S., E.S., S.S., E.W., J.G.M. Project administration: M.M.M., J.G.M. Resources: J.G.M. Software: M.M.M., S.S., L.L., J.G.M. Supervision: M.J.G., M.M.M.; C.K., L.L., S.S., E.W., J.G.M. Validation: M.M.M., J.G.M. Visualization: R.S.R., M.M.M., E.S., J.G.M. Writing一original 
draft: R.S.R, M.J.G., M.M.M., S.S., L.L., E.S., S.K., J.G.M. Writing-review \& editing: R.S.R., M.J.G., M.M.M., K.A., E.B., T.L.B., G.C., J.F.C., R.M.G., C.K., S.K., E.J..., L.L., C.A.S., E.S., S.S., E.W., S.P.W., J.G.M.

\section{ETHICS DECLARATION}

Informed consent was received from all participating study subjects. This study was approved by the Emory Institutional Review Board (IRB000088012).

\section{COMPETING INTERESTS}

C.A.S. reports receiving royalties from Pearson Clinical for the Vineland-3. The other authors declare no competing interests.

\section{ADDITIONAL INFORMATION}

The online version of this article (https://doi.org/10.1038/s41436-020-01053-1) contains supplementary material, which is available to authorized users.

Correspondence and requests for materials should be addressed to J.G.M.
Reprints and permission information is available at http://www.nature.com/ reprints

Publisher's note Springer Nature remains neutral with regard to jurisdictional claims in published maps and institutional affiliations.

(7) Open Access This article is licensed under a Creative Commons c. Attribution-NonCommercial 4.0 International License, which permits any non-commercial use, sharing, adaptation, distribution and reproduction in any medium or format, as long as you give appropriate credit to the original author(s) and the source, provide a link to the Creative Commons license, and indicate if changes were made. The images or other third party material in this article are included in the article's Creative Commons license, unless indicated otherwise in a credit line to the material. If material is not included in the article's Creative Commons license and your intended use is not permitted by statutory regulation or exceeds the permitted use, you will need to obtain permission directly from the copyright holder. To view a copy of this license, visit http://creativecommons.org/licenses/by-nc/4.0/.

(c) The Author(s) 2021

\section{THE EMORY 3029 PROJECT}

Hallie Averbach ${ }^{1}$, Gary J. Bassell ${ }^{10}$, Shanthi Cambala1, Tamara Caspary ${ }^{1}$, David Cutler ${ }^{1}$, Paul A. Dawson ${ }^{2}$, Michael P. Epstein ${ }^{1}$, Henry R. Johnston ${ }^{1}$, Bryan Mak ${ }^{1}$, Tamika Malone ${ }^{1}$, Trenell Mosley ${ }^{1}$, Ava Papetti ${ }^{1}$, Rebecca M. Pollak ${ }^{1}$, Ryan Purcell ${ }^{1,10}$, Nikisha Sisodoya ${ }^{1}$, Steven Sloan ${ }^{1}$, Stephen T. Warren ${ }^{1}$, David Weinshenker ${ }^{1}$, Zhexing Wen ${ }^{10}$ and Mike Zwick $^{1}$

${ }^{10}$ Department of Cell Biology, Emory University School of Medicine, Atlanta, GA, USA. 